\title{
Serial Kasus: Manajemen Anestesi pada Wanita Hamil dengan Plasenta Akreta yang Direncanakan Tindakan Seksio Sesarea
}

\author{
Purwoko, Rio Rusman, M. Ridho Aditya \\ Departemen Anestesiologi dan Perawatan Intensif, Rumah Sakit Dr. Moewardi, Fakultas Kedokteran Universitas \\ Sebelas Maret
}

\begin{abstract}
Abstrak
Perdarahan postpartum merupakan salah satu penyebab utama kematian ibu selain penyakit kardiovaskuler. Diantara penyebab perdarahan post partum adalah plasenta akreta dimana insidennya semakin meningkat dari tahun ke tahun seiring dengan peningkatan jumlah persalinan dengan seksio sesarea. Kami laporkan dua kasus ibu hamil dengan plasenta akreta yang direncanakan tindakan seksio sesarea emergency yang dikelola dengan general anesthesia rapid sequence induction. Kasus pertama, perempuan berusia 31 tahun G3P1A1 usia kehamilan 36-37 minggu dalam persalinan, perdarahan antepartum ec plasenta previa totalis, plasenta akreta dengan hemodinamik stabil. Intraoperatif, perdarahan sekitar $7000 \mathrm{cc}$, dan diberikan transfusi 8 unit PRC, 4 unit WB, 4 unit FFP, dan 4 unit Tc. Pascaoperasi pasien dirawat di ICU, dan komplikasi yang terjadi produk drain abdomen sekitar 1900 cc bercampur darah. tidak ada komplikasi mayor lainnya, pasien pindah ruang rawat inap pada hari keempat pascaoperasi. Kasus kedua, perempuan berusia 40 tahun G3P2A0 usia kehamilan 37-38 minggu dalam persalinan, perdarahan antepartum ec plasenta previa totalis, plasenta akreta dengan hemodinamik stabil. Intraoperatif, perdarahan sekitar $9000 \mathrm{cc}$, dan dilakukan transfusi 8 unit PRC, 8 unit WB, 4 unit FFP, dan 4 unit Tc. Pascaoperasi pasien dirawat di ICU, dan. tidak ada komplikasi signifikan terjadi. Hari kedua pascaoperasi pasien pindah ke ruang rawat inap.
\end{abstract}

Kata kunci: anestesi; akreta; plasenta; seksio; sesarea

\section{Case Series: Anesthesia Management in Pregnant Woman with Placenta Accreta Planned for Caesarean Section}

\begin{abstract}
Postpartum hemorrhage is one of the leading causes of maternal morbidity besides cardiovascular disease. Among the causes of postpartum hemorrhage is placenta accreta, where the incidence increases from year to year along with the increase in the number of cesarean delivery. We report two cases of pregnant women with placenta accreta planned for emergency cesarean section managed with general anesthesia rapid sequence induction. The first case, 31-year-old woman G3P1A1 36-37 weeks of gestation in labor, antepartum hemorrhage ec placenta previa totalis, placenta accreta with hemodynamically stable. During procedure, blood loss about $7000 \mathrm{cc}$, and given transfusion of 8 units of PRC, 4 units of WB, 4 units of FFP, and 4 units of Tc. In the end of procedure, the patient was transferred to intensive care unit, and complications that occurred around $1900 \mathrm{cc}$ of abdominal drain product mixed with blood. After that, there were no other major complications, then the patient moved the ward on the fourth day. The second case, a 40-year-old woman G3P2A0 37-38 weeks of gestation in labor, antepartum hemorrhage ec placenta previa totalis, placenta accreta with hemodynamically stable. During procedure, blood loss about $9000 \mathrm{cc}$, and given transfusion of 8 units of PRC, 8 units of WB, 4 units of FFP, and 4 units of Tc. In the end of procedure, the patient was transferred to intensive care unit, and no significant complications happen. The second day after surgery the patient moved to the ward.
\end{abstract}

Key words: anaesthesia; accreta; placenta; section; cesarean 


\section{Pendahuluan}

Plasenta akreta didefinisikan sebagai implantasi abnormal dari vili plasenta yang menginvasi miometrium tanpa adanya desidua basalis. Sindrom plasenta akreta adalah sindrom yang menggambarkan implantasi abnormal plasenta, plasenta invasif atau adesif. Termasuk berbagai implan plasenta dengan adesi abnormal ke miometrium yang disebabkan oleh tidak adanya desidua basalis baik sebagian atau total, dan pembentukan fibrinoid yang tidak sempurna dan lapisan Nitabuch. ${ }^{1,2}$ Peningkatan frekuensi sindrom plasenta akreta sejak 50 tahun terakhir berasal dari peningkatan persalinanseksio sesarea. Pada tahun 1924, Polak dan Phelan mempresentasikan data mereka dari Rumah Sakit Long Island College, di mana satu kasus plasentaakreta terjadi sebagai komplikasi dari 6000 persalinan. Pada ulasan tahun 1951, angka kematian ibu tercatat meningkat $65 \%$. Pada tahun 1971, dalam Williams Obstetrics edisi ke-14, satu penelitian menggambarkan plasenta akreta sebagai laporan kasus. Pada ulasan pada tahun berikutnya, satu penelitian mencatat rata-rata insiden 1 dari 7.000 persalinan yang dilaporkan. Sejak dilaporkan, terdapat peningkatan sindrom plasenta akreta, yang berhubungan langsung dengan peningkatan jumlah persalinan seksio sesarea. ${ }^{1,2}$

Insiden plasenta akreta yang dilaporkan meningkat yang awalnya dari 0,8 per 1.000 persalinan pada 1980 -an menjadi 3 per 1.000 persalinan selama 10 tahun terakhir. Pada sebuah penelitian observasional prospektif mempertimbangkan jumlah kelahiran pertama dengan seksio sesareadan ada atau tidak adanya plasenta previa, risiko plasenta akreta sebesar $0,03 \%$ untuk pasien dengan seksio sesareapertama kali jika tidak ditemukan plasenta previa, 1\% untuk wanita yang telah menjalani seksio sesarea ke-5, dan meningkat menjadi $4,7 \%$ untuk mereka yang menjalani seksio sesarea ke-6. Jika terdapat plasenta previa, risiko plasenta akreta sebesar 3\% pada mereka yang memiliki seksio sesareapertama dan meningkat menjadi $40 \%$ atau lebih pada mereka yang memiliki persalinan dengan seksio sesarea 3 kali. ${ }^{3,4}$
Patogenesis plasenta akreta masih tidak jelas, tetapi beberapa teori telah diajukan: vaskularisasi abnormal yang dihasilkan dari jaringan parut setelah operasi dengan hipoksia sekunder akibat penghancuran desidualisasi dan invasi trofoblas yang berlebihan kemungkinan menjadi yang paling menonjol, atau teori yang paling didukung hingga saat ini, menjelaskan patogenesis plasenta akreta pada tahap ini. ${ }^{5}$

Sebagian besar pasien dengan plasenta akreta tidak menunjukkan gejala. Gejala yang terkait dengan plasenta akreta dapat meliputi perdarahan dan kram pada vagina. Temuan tersebut sebagian besar terlihat pada kasus dengan plasenta previa, yang merupakan faktor risiko terkuat untuk terjadinya plasenta akreta. Meskipun jarang, kasus-kasus dengan nyeri perut akut dan hipotensi akibat syok hipovolemik akibat ruptur uteri sekunder dapat disebabkan oleh plasenta akreta. Implantasi plasenta yang abnormal hingga menyebabkan invasif plasenta yang menembus dinding rahim dapat menyebabkan atonia uterus karena pelepasan yang tidak lengkap atau perdarahan di dasar plasenta. Skenario kritis tersebut dapat terjadi kapan saja selama kehamilan dari trimester pertama hingga masakehamilan tanpa adanya tanda-tanda persalinan. ${ }^{5}$ Keberhasilan dalam menegakkan diagnosis plasenta akreta sebelum persalinan melibatkan perencanaan multidisiplin dalam meminimalisir potensi morbiditas dan mortalitas ibu.

Diagnosis dapat ditegakkan dengan pemeriksaan ultrasonografi (USG) dan kadang-kadang membutuhkanpemeriksaanMRI.Jikahisterektomi telah dilakukan, pemeriksaan patologi anatomi dapat dilakukan. ${ }^{6}$ Oleh karena pertimbangan hemodinamik yang tidak stabil dan potensi transfusi yang masif, sebagian besar praktisi melakukan anestesi umum untuk memfasilitasi prosedur seksio sesarea pada plasenta akreta. Namun, dalam penelitian sebelumnya di lima lembaga pada 1980 -an, terdapat $32 \%$ prosedur sesar histerektomi yang difasilitasi oleh anestesi regional, dan tidak ada perbedaan perdarahan intraoperatif atau kejadian hipotensi, dan tidak ada yang dikonversi menjadi anestesi umum. ${ }^{7}$ Perawatan pasca operasi ditujukan untuk 
mengevaluasi komplikasi yang dapat timbul termasuk kerusakan pada berbagai organ, disseminated intravascular coagulation (DIC), perdarahan dan transfusi masif, tromboemboli pascaoperasi, infeksi hingga kematian. ${ }^{8}$

\section{Kasus 1}

Anamnesa

Perempuan 31 tahun dengan berat badan $58 \mathrm{~kg}$, tinggi badan $157 \mathrm{~cm}$, G3P1A1 usia kehamilan 36-37 minggu, datang sendiri ke RSUD dr. Moewardi dengan keluhan kontraksi teratur disertai perdarahan dari jalan lahir sebanyak 2 pembalut penuh sejak 1 jam sebelum masuk RS. Sepuluh hari sebelumnya pasien pernah dirawat dengan perdarahan jalan lahir dan diagnosis antepartum hemoragik, plasenta previa totalis, dan morbidly adherent placenta (resiko tinggi). Awalnya pasien direncanakan untuk operasi seksio sesarea pada 1 minggu ke depan. Karena pasien sudah masuk masa persalinan sebelum waktu yang direncanakan, maka direncanakan seksio sesarea emergency. Pasien riwayat seksio sesarea dengan anestesi neuraksial tahun 2009. Tidak ada riwayat penyakit penyerta lainnya.

\section{Pemeriksaan Fisik}

Pasien dalam keadaan sadar GCS E4V5M6, dengan tekanan darah 130/70 $\mathrm{mmHg}$, laju nadi $109 \mathrm{bpm}$, kuat angkat, laju nafas $18 \mathrm{x} / \mathrm{i}$. Pemeriksaan jantung paru dalam batas normal. Akral hangat, merah, dan CRT $<2$ detik. Denyut jantung janin $130 \mathrm{bpm}$. Produksi urin $50 \mathrm{cc} / \mathrm{jam}$ warna jernih.

\section{Pemeriksaan Penunjang}

Data hematologi rutin (tabel 1) didapatkan anemia ringan. Pemeriksaan USG kandungan tampak plasenta insersi di segmen bawah rahim hingga menutupi orifisium uterus interna.

\section{Pengelolaan Anestesi}

Pasien ini dengan status fisik ASA 2E rencana seksio sesario hingga histerektomi dengan general anesthesia rapid sequence induction. Pasien dan keluarga diedukasi untuk menjalani operasi dengan anestesi umum, dan tindakan operasi resiko tinggi perdarahan banyak. Pasien
Tabel 1. Hasil Pemeriksaan Laboratorium Preoperasi

\begin{tabular}{lll}
\hline Pemeriksaan & Hasil & Satuan \\
\hline Hemoglobin & 10,0 & $\mathrm{~g} / \mathrm{dl}$ \\
Hematokrit & 31 & $\%$ \\
Leukosit & 9.000 & $/ \mathrm{mcl}$ \\
Trombosit & 252.000 & $/ \mathrm{mcl}$ \\
PT & 12,4 & detik \\
APTT & 30,3 & detik \\
INR & 0,940 & \\
GDS & 74 & mg/dl \\
\hline
\end{tabular}

disiapkan 2 jalur akses intravena dengan iv cath no 18. Pasien dipuasakan dan diberikan premedikasi dengan metoclopramid $10 \mathrm{mg}$ dan ranitidin 50 $\mathrm{mg}$ iv. Produk darah disiapkan 4 unit PRC, 4 unit FFP dan 4 unit TC. Karena perdarahan tidak aktif, dan hemodinamik stabil, operasi dimulai saat produk darah telah siap di bank darah. di kamar operasi, pasien diposisikan supine, sedikit head up, pinggul kanan diganjal. Tanda vital awal tekanan darah 122/70 mmHg, laju nadi $122 \mathrm{bpm}$, laju nafas $22 \mathrm{x} / \mathrm{i}$. Induksi menggunakan fentanyl $50 \mathrm{mcg}$, ketamine $50 \mathrm{mg}$, propofol $50 \mathrm{mg}$, dan rocuronium $50 \mathrm{mg}$ iv, kemudian pasien diintubasi menggunakan ETT no 7.0, pemeliharaan anestesi dengan $\mathrm{N}_{2} \mathrm{O}$ dalam oksigen $50 \%$ dan sevofluran hingga $0,5-1$ vol\%.

Asam tranexamat 1 gr iv diberikan 2 kali, saat diawal operasi, dan 2 jam berikutnya. Pasien dipakaikan warmer blanket untuk mencegah hipotermi. Di medan operasi, tampak vaskularisasi di segmen bawah rahim menembus lapisan serosa, dan diputuskan untuk dilakukan sesarean histerektomi. Selama operasi, perdarahan sekitar $7000 \mathrm{cc}$, cairan yang masuk ringer laktat $2500 \mathrm{cc}$, gelofusin $1000 \mathrm{cc}$, transfusi 8 unit PRC, 4 unit WB, 4 unit FFP, dan 4 unit Tc. Produksi urin 60 cc/jam. Ca glukonas $1 \mathrm{gr}$ iv bolus pelan diberikan 2 kali. Status hemodinamik intraoperatif (gambar 1) cenderung stabil dengan tekanan darah sistolik dipertahankan dalam kisaran $80-90 \quad \mathrm{mmHg}$ dengan vasopressor ephedrin.

\section{Pengelolaan Pascabedah}

Di akhir prosedur, ETT tetap dipertahankan 


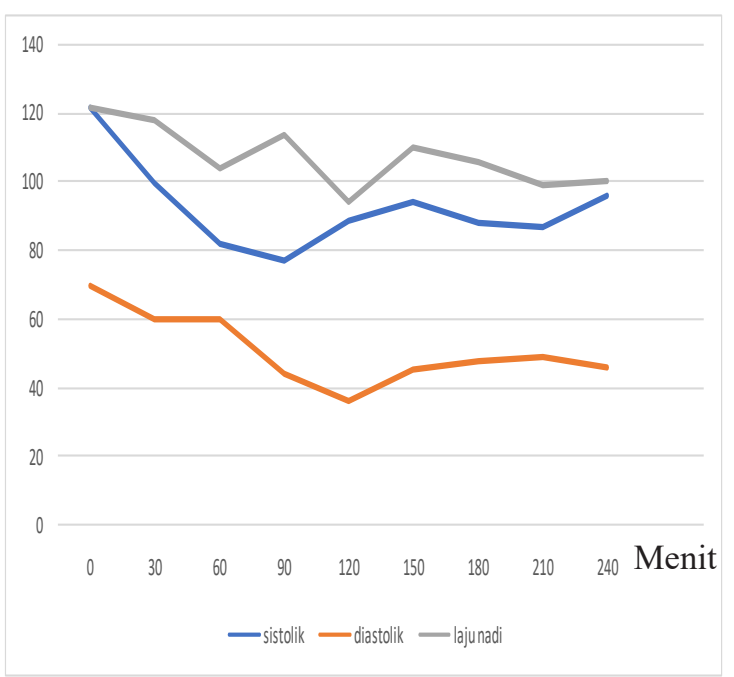

Grafik 1. Hemodinamik Pasien 1

dan pasien dirawat di ruang perawatan intensif. Manajemen nyeri diberikan fentanyl $30 \mathrm{mcg} / \mathrm{jam}$ sp, dan parasetamol $1 \mathrm{gr} / 8$ jam iv. Pascaoperasi, pemeriksaan laboratorium (tabel 2) didapatkan kadar hemoglobin adalah 6,2 g/dl.

Ditransfusi 2 unit PRC, dan ca glukonas $1 \mathrm{gr}$ iv. Dua puluh empat jam setelah operasi, produk drain abdominal mencapai 1.900 cc kemerahan, kadar hemoglobin $5,7 \mathrm{~g} / \mathrm{dl}$, trombosit $54.000 / \mathrm{mcl}$, calcium ion $0,89 \mathrm{mmol} / \mathrm{l}$, dikoreksi 4 unit PRC, dan ca glukonas 1 gr iv (2 kali). Dua hari paska operasi pasien stabil dan dilakukan ekstubasi. Pasien dipindahkan ke ruang rawat inap pada hari keempat pascaoperasi.

\section{Kasus 2}

\section{Anamnesa}

Perempuan berusia 40 tahun, $78 \mathrm{~kg}, 152 \mathrm{~cm}$, G3P2A0 usia kehamilan 37-38 minggu yang telah masuk masa persalinan dengan riwayat 2 kali seksio sesarea tahun 2001 dan 2005, dirujuk ke Rumah Sakit Dr. Moewardi, Surakarta setelah diperiksa oleh dokter kandungan di RS sebelumnya dan dicurigai dengan plasenta akreta. Pasien kontrol rutin dengan bidan, dan 2 kali kontrol dengan dokter kandungan. Datang dengan keluhan kontraksi teratur disertai perdarahan dari jalan lahir sebanyak 4 pembalut penuh sejak 3 jam SMRS. Tidak ada riwayat
Tabel 2. Hasil Pemeriksaan Laboratorium Paska Operasi

\begin{tabular}{lll}
\hline Pemeriksaan & \multicolumn{1}{c}{ Hasil } & \multicolumn{1}{c}{ Satuan } \\
\hline Hemoglobin & 6,2 & $\mathrm{~g} / \mathrm{dl}$ \\
Hematokrit & 20 & $\%$ \\
Leukosit & 11.600 & $/ \mathrm{mcl}$ \\
Trombosit & 101.000 & $/ \mathrm{mcl}$ \\
PT & 16,5 & detik \\
APTT & 30,2 & detik \\
INR & 1,350 & \\
Albumin & 2,2 & $\mathrm{~g} / \mathrm{dl}$ \\
Ureum & 27 & $\mathrm{mg} / \mathrm{dl}$ \\
Creatinin & 0,5 & $\mathrm{mg} / \mathrm{dl}$ \\
Natrium & 137 & $\mathrm{mmol} / 1$ \\
Kalium & 3,4 & $\mathrm{mmol} / 1$ \\
Chlorida & 103 & $\mathrm{mmol} / 1$ \\
Calcium ion & 1,02 & $\mathrm{mmol} / 1$ \\
\hline
\end{tabular}

penyakit penyerta lainnya. Riwayat seksio sesarea sebelumnya dengan neuraksial anestesi.

\section{Pemeriksaan fisik}

Pada pemeriksaan fisik didapatkan pasien dalam keadaan sadar GCS E4V5M6 dengan tekanan darah 110/78 mmHg, denyut jantung 110 bpm, kuat angkat, laju respirasi $22 \mathrm{x} / \mathrm{i}$. pemeriksaan jantung paru dalam batas normal. Konjungtiva tampak anemis. Akral hangat, sedikit pucat, dan CRT $<2$ detik. Denyut jantung janin 148 bpm.

Pemeriksaan Penunjang

Pemeriksaan laboratorium (tabel 3) didapatkan anemia dengan $\mathrm{Hb}$ 9,3 g/dl. Pemeriksaan USG kandungan tampak insersi plasenta di segmen bawah rahim anterior hingga menutupi orifisium uteri interna, dan tampak lakuna besar.

\section{Pengelolaan Anestesi}

Dari sistem scoring Morbidly Adherent Placenta (MAP) masuk kategori probabilitas tinggi MAP. Assessment pasien dengan perdarahan antepartum ec plasenta previa totalis, MAP (resiko tinggi), rencana seksio sesarea emergency dengan status fisik ASA 2E. Pada kasus ini kami memutuskan untuk menggunakan teknik general anesthesia 
Tabel 3. Hasil Pemeriksaan Laboratorium Preoperasi

\begin{tabular}{lll}
\hline Pemeriksaan & \multicolumn{1}{c}{ Hasil } & Satuan \\
\hline Hemoglobin & 9,3 & $\mathrm{~g} / \mathrm{dl}$ \\
Hematokrit & 32 & $\%$ \\
Leukosit & 16.100 & $/ \mathrm{mcl}$ \\
Trombosit & 189.000 & $/ \mathrm{mcl}$ \\
PT & 11,0 & detik \\
APTT & 24,4 & detik \\
INR & 0,950 & \\
\hline
\end{tabular}

rapid sequence induction. Keluarga di inform consent prosedur pembiusan dan resiko yang mungkin terjadi selama operasi. Darah disiapkan 4 unit PRC, 4 unit FFP, 4 unit Tc. Oleh karena status hemodinamik pra-operasi pasien masih stabil, operasi dimulai setelah darah siap di bank darah. Akses intravena dipasang dua jalur dengan iv cath no. 18. Pasien dipuasakan, dan diberikan metoclopramide $10 \mathrm{mg}$ iv dan ranitidin $50 \mathrm{mg}$ iv sebagai profilaksis pneumonitis aspirasi. Sambil menunggu persiapan selesai, pasien dipantau tanda-tanda vital, perdarahan, dan denyut jantung janin.

Di kamar operasi, pasien diposisikan supine sedikit head up dan diganjal pinggul kanan. Operator diminta untuk mempersiapkan medan operasi, agar insisi dapat dilakukan segera setelah intubasi terkonfirmasi. Akses vena sentral dipasang sebelum induksi, menimbang pasien obesitas dan kemungkinan kesulitan jika dilakukan durante operasi. Preoksigenasi dengan oksigen $100 \%$ tanpa ventilasi tekanan positif, lanjut fentanyl $50 \mathrm{mcg}$, rocuronium $50 \mathrm{mg}$, ketamin $70 \mathrm{mg}$ dan propofol $30 \mathrm{mg}$ iv. Intubasi oral dengan ETT no. 7.0 level $20 \mathrm{~cm}$. Pemeliharaan anestesi dengan $\mathrm{N}_{2} \mathrm{O}$ dalam oksigen $50 \%$ dan sevofluran $0,5-1$ vol\%. Selanjutnya diberikan asam traneksamat $1 \mathrm{gr}$ iv, dan diasang warmer blanket. Ahli kandungan memutuskan untuk langsung dilakukan histerektomi. Saat perkiraan perdarahan $500 \mathrm{cc}$ dan belum terkontrol, transfusi mulai diberikan. Perdarahan selama operasi mencapai 9.000 cc. Dilakukan tranfusi 8 unit PRC, 8 unit WB, 4 unit FFP, dan 4 unit Tc. Ca

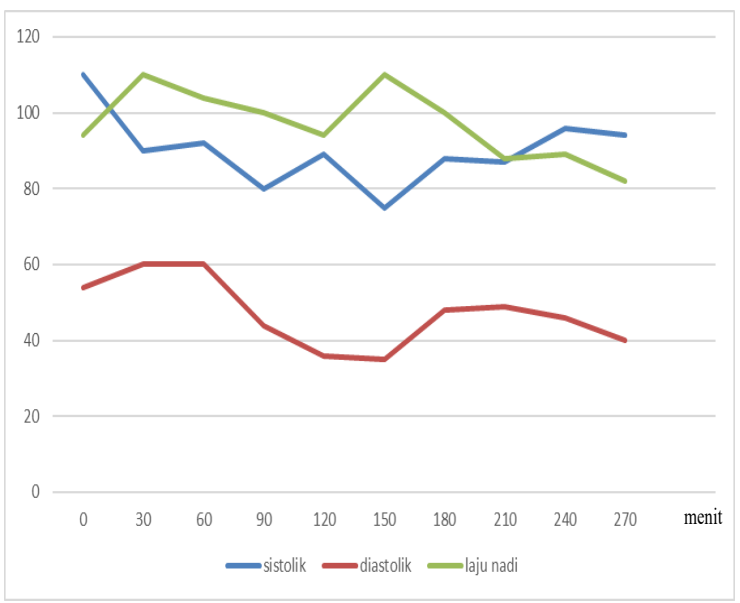

Gambar 2. Grafik Hemodinamik Pasien 2

glukonas 1 gr iv diberikan 2 kali. Produksi urin $40 \mathrm{cc} / \mathrm{jam}$. Hemodinamik selama operasi (gambar 2) dipertahankan sistolik $80-90 \mathrm{mmHg}$.

\section{Pengelolaan Pascabedah}

Di akhir operasi, pasien tidak diekstubasi dan dirawat di ICU, menimbang paska transfusi dalam jumlah besar, adanya kemungkin komplikasi di sistem respirasi. Untuk pengelolaan nyeri diberikan morfin 0,5-1mg/jam sp, dan paracetamol $1 \mathrm{gr} / 8 \mathrm{jam}$ iv. pemeriksaan laboraorium paska operasi (tabel

\section{Tabel 4. Hasil Pemeriksaan Laboratorium} Paska Operasi

\begin{tabular}{lll}
\hline Pemeriksaan & \multicolumn{1}{c}{ Hasil } & \multicolumn{1}{c}{ Satuan } \\
\hline Hemoglobin & 7,2 & $\mathrm{~g} / \mathrm{dl}$ \\
Hematokrit & 23 & $\%$ \\
Leukosit & 14.100 & $/ \mathrm{mcl}$ \\
Trombosit & 89.000 & $/ \mathrm{mcl}$ \\
PT & 17,0 & detik \\
APTT & 34,0 & detik \\
INR & 1,500 & \\
Albumin & 2,4 & $\mathrm{~g} / \mathrm{dl}$ \\
Ureum & 31 & $\mathrm{mg} / \mathrm{dl}$ \\
Creatinin & 0,6 & $\mathrm{mg} / \mathrm{dl}$ \\
Natrium & 133 & $\mathrm{mmol} / 1$ \\
Kalium & 3,6 & $\mathrm{mmol} / 1$ \\
Chlorida & 100 & $\mathrm{mmol} / 1$ \\
Calcium ion & 0,96 & $\mathrm{mmol} / 1$ \\
\hline
\end{tabular}


4) didapatkan anemia, trombositopenia, dan hipocalcemia. Dikoreksi dengan 1 unit PRC, ca glukonas $1 \mathrm{gr}$ iv. Tidak ada komplikasi yang signifikan. Pasien diekstubasi besoknya. Hari kedua pascaoperasi pasien pindah ke ruang rawat inap.

\section{Pembahasan}

Evaluasi dan rencana pra-anestesi untuk pasien antenatal yang dianggap berisiko tinggi terjadinya perdarahan merupakan hal yang penting. Peran ahli anestesi idealnya akan dimulai jauh sebelum pasien tiba di ruang bersalin. Konsultasi antepartum, pra-anestesi sebagai pasien rawat jalan merupakan langkah penting dalam mempersiapkan dan menggambarkan rencana untuk wanita yang dianggap berisiko tinggi mengalami pendarahan selama persalinan. Penting untuk berkolaborasi dengan ahli kandungan untuk mengevaluasi kecurigaan Morbidly Adherent Placenta berdasarkan beberapa kriteria pada tabel 5 dibawah ini. ${ }^{9}$ Optimalisasi preoperatif sangat penting dalam memitigasi masalah yang mungkin muncul pada ibu hamil dengan resiko tinggi.

Mulai dari edukasi keluarga (tentang rencana manajemen anestesi, resiko dan komplikasi yang mungkin terjadi selama prosedur operasi), akses intravena yang adekuat, monitoring invasif jika diperlukan, persiapan obat emergency, hingga persiapan produk darah. Anestesi umum ataupun regional dapat digunakan pada kondisi ini. Akan tetapi, sebagian besar ahli anestesi lebih memilih untuk melakukan anestesi umum dengan pertimbangan resiko perdarahan masif, ventilasi yang terkontrol, dan hemodinamik yang lebih stabil selama prosedur. Satu penelitian juga melaporkan anestesi umum pada pada kasus plasenta perkreta dengan komorbid DM tipe II. ${ }^{10}$ Namun ada beberapa hal yang harus diperhatikan bila memberikan anestesi umum pada ibu hamil, yaitu resiko aspirasi dan kemungkinan kesulitan intubasi. Untuk mengurangi resiko aspirasi direkomendasikan ibu hamil untuk puasa 6 jam (makanan ringan) dan 8 jam (makanan berat) preoperasi, profilaksis dengan antasid non partikulat 30 menit sebelum
Tabel 5. Kriteria untuk mengevaluasi Morbidly Adherent Placenta

\begin{tabular}{ll}
\hline Parameter & Nilai \\
\hline Riwayat seksio sesaria sebelumnya & 1 \\
1 & 2 \\
$\geq 2$ & \\
Ukuran lakuna & 1 \\
$\leq 2 \mathrm{~cm}$ & 2 \\
$>2 \mathrm{~cm}$ & \\
Jumlah lakuna & \\
$\leq 2$ & 1 \\
$>2$ & 2 \\
Batas uteroplasenta tak tampak & 2 \\
Lokasi plasenta & \\
Anterior & 1 \\
Plasenta previa & 2 \\
Penilaian doppler & \\
Blood flow di lakuna & \\
Hipervaskularitas di perbatasan plasenta- \\
vesika urinaria dan/atau uteroplasenta
\end{tabular}

operasi, obat $\mathrm{H} 2$ antagonist, dan prokinetik (metoclopramide). ${ }^{11}$ Pada kasus ini kami hanya memberikan metocolpramide dan ranitidine, karena antasid non partikulat tidak tersedia. Riwayat SC sebelumnya merupakan faktor risiko untuk terjadinya plasenta akreta pada pasien ini. Ditambah dengan adanya plasenta previa totalis yang ditandai oleh perdarahan dari jalan lahir selama kontraksi, kemungkinan plasenta akreta menjadi pertimbangan penting. ${ }^{3}$ Hal tersebut diperkuat oleh skor dari Morbidly Adherent Placenta yang masuk dalam kategori risikotinggi, sehingga risiko perdarahan perioperatif tinggi juga. Oleh karena itu, pada kasus ini kami memutuskan untuk menggunakan teknik rapid sequence induction general anesthesia. Oleh karena status hemodinamik pra operasi pasien masih stabil, operasi dimulai setelah darah siap di bank darah. Pemantauan ketat intraoperatif merupakan kunci untuk manajemen pasien yang berisiko perdarahan masif. Menurut pedoman 
American Society of Anesthesiologist (ASA) 2006, transfusi PRC sebaiknya diberikan bila kadar hemoglobin dibawah $6 \mathrm{gr} / \mathrm{dl}$. Hal ini disesuaikan dengan kondisi masing-masing pasien agar delivery oxygen tetap tercukupi. Namun pada kondisi on going bleeding, ahli anestesi dapat memulai transfusi pada $\mathrm{Hb}$ diatas $7 \mathrm{gr} / \mathrm{dl} .{ }^{12}$ Begitu juga rekomendasi dari European Society of Anesthesiology, pada perdarahan aktif, target $\mathrm{Hb}$ 7-9 gr/dl, dengan menilai secara berkala kadar hematokrit/hemoglobin, laktat serum, base excess untuk memonitor perfusi dan oksigenasi jaringan. ${ }^{13}$ Pada kasus ini, inisiasi transfusi berdasarkan perhitungan allowable blood loss (ABL), ketika medekati nilai $\mathrm{ABL}$, maka transfusi segera diberikan. Hal ini menimbang untuk pemeriksaan lab yang butuh waktu dan perdarahan yang masif dan berlangsung cepat.

Fraksi oksigen inspirasi dapat diberikan cukup tinggi untuk mencegah hipoksemia, dan menghindari hiperoksia $\left(\mathrm{PaO}_{2}>200 \mathrm{mmHg}\right)$. Tekhnik hemodilusi normovolemik akut dapat digunakan, akan tetapi tidak kombinasikan dengan tekhnik hipotensi kendali. ${ }^{13,14}$ Hipotensi permisif dengan target tekanan darah sistolik $80-90 \mathrm{mmHg}$ (MAP 50-60 $\mathrm{mmHg}$ ) dapat dipakai hingga perdarahan aktif telah terkontrol. Vasopressor dapat diberikan untuk mempertahankan tekanan arteri pada hipotensi berat. Dan agen inotropik diberikan pada disfungsi miokard. ${ }^{15}$ Untuk mencegah koagulopati pada perdarahan massif dapat diberikan transfusi FFP, Tc, dan fibrinogen concentrate. Penggunaan cell salvage dapat mengurani transfusi paska operasi dan lama rawat. Kalsium memainkan peran penting dalam kaskade pembekuan darah, serta risiko hipokalsemia dalam transfusi masif, sehingga diberikan suplemen kalsium. Pemberian asam traneksamat sebagai anti-fibrinolitik diberikan setelah bayi lahir dan dilanjutkan setelah operasi. Selain itu, juga merekomendasikan asam traneksamat diberikan sebelum SC terutama pada perdarahan antepartum, dan diberikan lagi jika perdarahan berlanjut. ${ }^{13,14}$

Untuk mengoptimalkan transfusi dan pemberian cairan, kami menempatkan kateter vena sentral pada pasien ini. Dalam hal ini, menggunakan teknik hipotensi kendali sambil mempertahankan cairan yang cukup dengan target menghasilkan urin $0,5-1 \mathrm{cc} / \mathrm{kg} / \mathrm{jam}$. Pemilihan agen anestesi yang dapat memperburuk kondisi pasien juga harus dihindari untuk hasil yang diharapkan. Pemantauan paska operasi dilakukan di ICU untuk pemantauan dan pemantauan intensif dan menilai apakah ada komplikasi yang timbul dari tindakan yang diambil.

\section{Simpulan}

Manajemen anestesi pasien dengan perdarahan selama persalinan dari periode antenatal ke periode postpartum adalah hal yang penting. Manajemen perdarahan yang optimal selama persalinan melibatkan perawat, dokter kandungan dan dokter anestesi agar dapat mengenali sejak dini potensi perdarahan yang berlebihan dan memulai" protokol perdarahan masif obstetri" yang menjelaskan tugas-tugas khusus untuk setiap anggota tim dan algoritma yang harus diikuti sesuai dengan etiologi, keadaan dan waktu selama persalinan. Implementasi algoritma dan protokol untuk transfusi masif dan sumber daya tambahan, klarifikasi setiap tugas, peningkatan proses komunikasi, pembekalan dan audit, dan pengenalan peran penting tim anestesiologi selama langkah-langkah ini sangat penting. Mempersiapkan perawatan pasien ke tingkat perawatan yang lebih tinggi (ICU) ketika dibutuhkan sangat penting, dan protokol nyeri pascapersalinan yang disesuaikan akan meningkatkan pemulihan setelah melahirkan seperti pada perdarahan obstetrik masif.

\section{Daftar Pustaka}

1. Cunningham FG, Leveno KJ, Blum SL. Williams Obstetrics 24th ed. 2014, 804-8.

2. Bowman ZS, Eller AG, Kennedy AM. Accuracy of ultrasound for the prediction of placenta accrete. American Journal of Obstetrics and Gynecology. 2014; 211(2), 177.e1-177.e7.

3. Belfort, Michael A. Publication committee, society for maternal-fetal Medicine. 
American Journal of Obstetrics and Gynecology: Placenta Accreta. 2010; 430 37.

4. Jauniaux E, Chantrain F, Silver RM, Langhoff-Ross, J. FIGO consensus guidelines on placenta accreta spectrum disorder: Epidemiology. International Journal of Gynecology Obstetrics. 2018;140(3):265-73.

5. Guleria K, Gupta B, Agarwal S, Suneja A, Vaid N, Jain S. Abnormally invasive placenta: changing trends in diagnosis and management. Acta Obstet Gynecol Scand. 2013; 92: 461-64.

6. Comstock CH. General obstetric sonography: prenatal diagnosis of placenta accreta. In: Arthur CF, Eugene CT, Wesley L, Frank AM, Roberto JR. Sonography in obstetric and gynecology 7th ed. Tennesse: McGraw-Hill. 2011.

7. Reitman E, Devine PC, Laifer-Narin SL, Flood P. Case scenario: perioperative management of a multigravida at 34 week gestation diagnosed with abnormal placentation. Anesthesiology. 2011; 115(4): 852-7.

8. Berkley EM, Abuhamad AZ. Prenatal diagnosis of placenta accreta. J Ultrasound Med. 2013; 32(8): 1345-50.

9. Tovbin J, Melcer Y, Shor S, Pekar-Zlotin M, Mendlovic S, Svirsky R, Maymon R, et al. Prediction of morbidly adherent placenta using a scoring system. Ultrasound Obstet Gynecol. 2016; 48: 504-10.

10. Mallawaarachci RP, Pallemulia R. Case report: perioperative anesthetic management of a pregnant mother with placenta percreta. 2018; 8(2): 99-101.

11. Frolich MA. Obstetric anesthesia. In: Butterworth JF, Mackey DC, Wasnick JD. Clinical anesthesiology 5th ed. United State: McGraw-Hill. 2013.

12. Mayer DC, Smith KA. Antepartum and postpartum hemorrhage. In: Chesnut $\mathrm{DH}$, Polley LS, Tsen LC, Wong CA. Obstetric anesthesia 4th ed. Philadelphia: Elsevier. 2009.

13. Kozek-langenecker SA, Ahmed AB, Afshari A, et al. Management of severe perioperative bleeding: guidelines from the european society of anaestheiology. Eur J anaesthesiol. 2017; 34: 332-95.

14. Chatrath V, Khetarpal R, Kaur H, Bala A, Magila M. Anesthetic consideration and management of obsteric hemorrhage. International Journal of Scientific Study. 2016; 4(5): 240-8.

15. Spahn DR, Bouillon B, Cerny V, Duranteau J, Filipescu D, Hunt BJ, et al. The european guideline on management of major bleeding and coagulopathy following trauma: fifth edition. Critical Care. 2019; 23(98): 2-74. 